\title{
Empirisk forskning om domstolar i Finland ${ }^{*}$
}

\author{
Mika Sutela, Östra Finlands universitet (Joensuu, Finland)
}

\begin{abstract}
The subject of my article-based dissertation in law was decision-making in the general courts of Finland. My research aimed to describe how uniform decisionmaking is in the Finnish courts. With regard to district courts convictions of aggravated drunk driving were the main focus of my study. The results show that there are regional differences in the sentences. Results are based on empirical legal research that draws on aspects of criminal and procedural law as well as criminology. Prior to this, only a few empirical studies had been conducted in Finland that focused on the courts and other criminal sanctioning systems. In the current dissertation, the equality and predictability of judicial decision-making act as theoretical starting points. The dissertation adopts a research tradition established at the international level where the influence of legal and extra-legal factors, e.g., offender age, on sentencing is explored. At a more theoretical level, the dissertation reflects the research tradition of legal realism. Empirical legal research will play an increasingly important role in the future. It can increase both equality before the law, as well as the transparency of decision-making and confidence in the judicial process.

Data on, e.g., punishments meted out by the courts, should be kept as current as possible since information on the functioning of the legal system is important. Empirical court research provides a unique basis for discussing levels of punishment. The functioning of the legal system has a major impact on society. Empirical data, including statistics, provide a good basis for a wide range of research.
\end{abstract}

\section{Doktorsavhandling om domstolars beslutsverksamhet}

Min avhandling inom det rättsliga området, Arbitrium an decisio - Oikeudellisen päätöksenteon yhtenäisyys yleisissä tuomioistuimissa (fri övers. det rättsliga beslutsfattandets enhetlighet i allmänna domstolar), ${ }^{1}$ som granskades i juni 2016 på Joensuu campus vid Östra Finlands universitet, behandlade verksamheten vid

* Title in English: Empirical research on Finnish courts. 
Finlands tingsrätter, hovrätter och högsta domstol. Doktorsavhandlingen handlar alltså om finska domstolars beslutsverksamhet. Syftet med undersökningen var att få fram information om hur enhetligt beslutsfattandet är i finska domstolar.

För tingsrätternas del granskades särskilt domar som getts för grovt rattfylleri. Undersökningsresultaten visar att det är möjligt att observera regionala skillnader i domarna. Tingsrättsspecifika skillnader i fördelningen av straffarter observerades i domar som gavs för grovt rattfylleri. Det är svårt att säga vad skillnaderna beror på. Antagligen påverkas detta av många olika faktorer. Det typiska straffet som dömdes ut för grovt rattfylleri var 60 dagar villkorligt fängelse jämte ett bötesstraff på 30 dagsböter. Det verkar som att villkorligt fängelsestraff tillsammans med tilläggsböter i rättspraxis har blivit en ny straffart som används regelbundet uttryckligen vid grovt rattfylleri.

Avhandlingen är en artikelavhandling som innehåller sex forskningsartiklar. Artiklarna framskrider i kronologisk ordning så att tingsrätternas avgöranden granskas först varefter hovrätternas beslutsfattande granskas och slutligen högsta domstolens prejudikat och avgöranden om extraordinärt ändringssökande. I undersökningen har som forskningsmaterial utnyttjats flera olika typers empiriska material, särskilt tingrätters, hovrätters liksom också högsta domstolens avgöranden. Därtill granskades Statistikcentralens officiella straff- och domstolsstatistik ${ }^{2}$ i undersökningens olika skeden. I artiklarna som ingick i avhandlingen användes statistikmaterial som samlats direkt ur tingsrätternas rättegångshandlingar, Statistikcentralens officiella straff- och hovrättsstatistik, material som samlats ur handlingar i arkivet över hovrättsavgöranden som upprätthålls av juridiska fakulteten vid Åbo universitet samt statistiskt material som samlats ur justitieministeriets Finlex-databas över högsta domstolens prejudikat.

\section{Undersökningens placering på kartan över forskningsinriktningar}

Undersökningen representerar empirisk rättsforskning som innehåller såväl straffrättsliga som processrättsliga drag samt också kriminologiska aspekter. Eftersom forskningsobjektet är allmänna domstolar, kan man säga att undersökningen utgör domstolsforskning. Internationellt sett har domstolar undersökts i viss utsträckning. Största delen av domstolsforskningen har gjorts av statsvetare. ${ }^{3}$ Även sociologer har varit aktiva domstolsforskare. Däremot har det juridiska perspektivet ofta fått mindre uppmärksamhet i domstolsforskningen. Vanligtvis har forskningen koncentrerat sig på att granska de högsta rättsinstanserna. Däremot har underrätterna, tingsrätternas avgöranden och deras verksamhet mera sällan varit föremål för forskning. 
I Finland har det å sin sida bedrivits relativt lite empirisk domstolsforskning och forskning med fokus på det straffrättsliga påföljdssystemet. Forskningen har i huvudsak koncentrerats till det rättspolitiska forskningsinstitutet som verkade under justitieministeriets förvaltningsområde, nuvarande institutet för kriminologi och rättspolitik vid Helsingfors universitet. I Finland har domstolar, deras beslutsfattande och bestämmande av straff undersökts i doktorsavhandlingar några enstaka gånger. Forskning med anknytning till bestämmande av straff som koncentrerar sig på straffrätt har bedrivits i viss mån i Finland, även på doktorsavhandlingsnivå. ${ }^{4}$ Avhandlingarna har dock snarare varit teoretiska än empiriska. Min doktorsavhandling innehåller också denna empiriska sida. Avhandlingens straffrättsliga element uppstår uttryckligen genom de normer som anknyter till bestämmande av straff och de empiriska resultaten.

Det rättsliga beslutsfattandets jämlikhet och förutsebarhet verkar som undersökningens teoretiska utgångspunkter. Typstrafftankesättets grundidé och kritiken av densamma behandlas också i avhandlingens sammanfattande del. Det kan också anses att avhandlingen i viss mån efterbildar den rättsrealistiska inriktningen. På internationell nivå placerar avhandlingen sig inom den etablerade forskningstraditionen, där man undersöker på vilket sätt rättsliga och icke-rättsliga faktorer (t.ex. gärningsmannens ålder, kön, socioekonomiska ställning osv.) påverkar bestämmandet av straff. Regionalitet (eller domstolen) kan anses vara en s.k. icke-rättslig faktor som påverkar straffets art och mängd. Straffrättskipningens jämlikhet och straffpraxisens enhetlighet var ett av de teman som var i mode inom den rättssociologiska forskningen under 1970-talet, när just faktorer som orsakar skillnader i dömande ${ }^{5}$ väckte särskilt intresse.

$\AA$ andra sidan kan underökningen på en mera teoretisk nivå anses efterbilda också rättsrealistisk forskning. Som en av grundidéerna med sociologisk rättsvetenskap och amerikansk realism kan i koncentrerad form anses vara att den rättsliga verkligheten består av domstolars rättskipande beslutsverksamhet. ${ }^{6}$ Uppmärksamheten fästs alltså vid domstolars och myndigheters avgöranden i stället för de »pappersregler « som lagstiftaren stiftat och rättslärda undersökt. ${ }^{7}$ Enligt rättsrealisterna är gällande rätt helt enkelt endast det som domare och andra aktörer som använder sig av rättslig makt i verkligheten gör. ${ }^{8}$ Till den skandinaviska realismens inriktning hörde tron på förnuft, vetenskap och teknik. Tanken var att människosläktets utveckling styrs av medveten, rationell planering istället för religion, myter och instinkt. Det har ansetts vara karakteristiskt för den skandinaviska realismen att normer behandlas som faktiska fenomen, vilka är en del av den sociala verkligheten. Alf Ross betonade det nära sambandet mellan rättsdogmatiken och rättssociologin. ${ }^{9}$ Enligt Aulis Aarnio har rättsvetenskaplig forskning 
som efterliknar Ross' realistiska tankesätt inte bedrivits i Finland. Det har inte funnits och det finns inte en levande rättsrealistisk tradition i Finland. ${ }^{10}$

\section{Teknologi som hjälp för förfaringssätten och beslutsfattandet?}

Datorer och den teknologiska utvecklingen kan möjliggöra effektivare och snabbbare arbete och beslutsfattande i domstolar, men också i andra rättsliga myndigheter. Den teknologiska utvecklingen kan i framtiden bra stöda myndigheters beslutsfattande och främja enhetligheten i avgörandepraxis. Digitala informationssystem kommer att omvälva domstolarnas förfaringssätt och öppna upp nya möjligheter för strukturella lösningar. ${ }^{11}$

Genom statistiskdata och analys kan man eventuellt utveckla beslutsfattandemodeller som erbjuder domstolar utgångspunkter för straffen, vilka efterliknar idén med typstrafftankesättet. Modellerna skulle inte kunna följas slaviskt, men med hjälp av dem skulle det ändå vara möjligt att erhålla någon slags fästpunkter som grund för straffmätningen, vilka kunde basera sig på flera faktorer som påverkar straffets art och mängd. ${ }^{12}$ Den slutliga beslutanderätten skulle kvarstå hos domaren, som skulle använda sig av sunt förnuft med beaktande av målets särdrag, och i enlighet med dessa döma ut ett strängare eller lindrigare straff jämfört med den statistiska utgångspunkten. Liksom Melander har konstaterat utgör straffmätning inte mekanisk verksamhet där man för en gärning som anses utgöra en viss brottstyps typfall mekaniskt bestämmer ett straff som följer av några vissa instruktioner. Då finns risken att man förbiser effekten av andra grunder som påverkar straffmätningen. ${ }^{13}$ Fastän jämlikhetsprincipen är en viktig princip får den inte leda till schablonmässiga modeller som i verkligheten ökar på oenhetlighet och risk för att man avviker från proportionalitetsprincipen ifall målen inte genuint är likadana. ${ }^{14}$

I högsta domstolens årsberättelse från år 2015 konstaterade högsta domstolens president Timo Esko att det i högsta domstolen finns ett behov att hitta redskap för effektivisering av målens behandling och reducering av behandlingstiderna. Ett möjligt sätt att erbjuda redskap för förbättring av arbetsmetoderna är att utveckla informationsteknologin. ${ }^{15}$ Det är just behandlingstiderna i domstolarna som lämpar sig som exempel på betydande empiriska forskningsobjekt i framtiden, eftersom behandlingstidernas längd i rättssystemets olika skeden har ökat markant under de senaste åren. Särskilt förundersökningarnas genomsnittliga längd hos polisen, långa tider av anhängighet vid åklagarämbetet och dröjsmål med prejudikat vid HD har blivit mer allmänna. ${ }^{16}$ 


\section{Den empiriska domstolsforskningens framtid}

Till finländska domstolar anknyts ofta en tanke om kontinuitet och stabilitet. Under det senaste decenniet har dock finländska domstolar, åklagarämbetet samt också polisen ändrats väsentligt både innehållsmässigt och organisatoriskt. $\AA$ andra sidan har också brottmålens handläggningsprocesser och påföljdssystemet ändrats. På grund av den snabba förändringstakten, och eftersom materialet i huvudsak härstammade från det senaste årtiondet, finns det vid granskningen av doktrosavhandlingens resultat skäl att beakta att forskningsresultaten inte speglar den nuvarande avgörandepraxisen, men säkerligen berättar de ändå riktgivande om rättspraxisens läge.

Förändringarna som skett under de senaste åren, och även förändringar som är på kommande, innebär att empirisk statistisk forskning om rättssystemet har en ännu viktigare ställning. Den empiriska rättsforskningen kan också öka på medborgarnas jämlikhet inför lagen. ${ }^{17}$ Genom empirisk forskning som riktar sig mot domstolar är det möjligt att öka på transparensen i beslutsverksamheten och således också på tilliten gentemot domstolarna. Det skulle också vara möjligt att utvidga forskningen om (rättsligt) beslutsfattande till exempelvis arbetsdomstolen, internationella domstolar, förvaltningsprocesser eller andra myndigheter än domstolar, såsom olika slags nämnder och andra besvärsorgan.

I framtiden behövs mera empirisk rättsforskning som baserar sig på aktuell information. Mer aktuell information borde finnas till hands, till exempel om just domstolarnas avgörandepraxis, eftersom information om rättssystemets verksamhet är viktig. Hur rättssystemet fungerar har trots allt stora effekter på hela samhället. Det skulle behövas mer statistisk forskning med fokus på straffpraxis. Olika straffarters straffnivåer tas rätt så ofta upp i offentligheten. Med hjälp av empirisk domstolsforskning kunde diskussionerna om straffnivåerna vara mer givande och föras på en högre kunskapsnivå. Det borde också finnas tillgång till mera uppföljningsinformation om effekterna av ändringar i lagstiftningen och rättssystemet, så att man bättre kunde bedöma olika ändringseffekter i efterhand. Empirisk rättsforskning med fokus på domstolars verksamhet erbjuder ett ypperligt redskap för detta. För att bedrivandet av statistisk empirisk rättsforskning ska vara möjlig, borde man i framtiden utveckla och förbättra tillgängligheten till de rättsliga empiriska materialen i Finland.

Det är förvånansvärt att exempelvis empirisk forskning som granskar rättsliga fenomen är ringa i Finland, fastän betydelsen av utvärderingskunskap och -forskning har framhävts mer och mer i beslutsfattandet. ${ }^{18}$ I Finland har på den senaste tiden talats mycket om avvecklandet av onödig reglering. Det skulle vara viktigt att skapa alltmer empirisk information om samhälleligt relevanta frågor som stöd 
för lagberedningen, så att onödig reglering kunde undvikas. Det är också väsentligt att utvärdera och följa lagstiftningens effekter.

Empiriskt material, bl.a. statistik, lägger en stabil grund för varierande forsknings- och utredningsarbeten. Ett statistiskt tillvägagångssätt lämpar sig väl för bildandet av ny information. I Finland har man fătt information om brottmål som behandlats i domstol sedan slutet av 1800-talet. Tidigare fanns det till och med rikligt med personuppgifter om gärningsmännen till uppseende i domstolsstatistiken, såsom skolgång, tidigare brottslighet och modersmål. ${ }^{19}$ Sedermera har dock domstolsstatistiken mer och mer gått från att vara en statistik som beskriver brottslighet och gärningsmän till en statistik som granskar domstolar och domstolars beslutsverksamhet. ${ }^{20}$ För nuvarande finns det, och det kommer också i framtiden att finnas, mindre aktuell domstolsstatistik än tidigare, eftersom Statistikcentralen år 2015 lade ner produktionen och publiceringen av statistik som gäller domstolars avgöranden. ${ }^{21}$

Ett av syftena med empirisk forskning är att minska på den osäkerhet som anknyter till beslutsfattande, till exempel genom att hitta regelbundenheter om det fenomen som undersöks. Till exempel i kriminalpolitiskt beslutsfattande måste man ofta ta stöd av prognoser. Ofta görs de kriminalpolitiska prognoserna dock främst utgående ifrån beslutsfattarens egna erfarenheter. Genom att utnyttja empiriska modeller kunde man göra mera exakta prognoser i jämförelse med enbart erfarenhetsbaserade prognoser, och prognoserna kunde utnyttjas i det kriminalpolitiska beslutsfattandet. ${ }^{22}$

\section{Noter}

1. Den elektroniska versionen av doktorsavhandlingen (Arbitrium an decisio - Oikeudellisen päätöksenteon yhtenäisyys yleisissä tuomioistuimissa. Publications of the University of Eastern Finland. Dissertations in Social Sciences and Business Studies No 117. Joensuu 2016.) kan läsas på UEF Electronic Publications-tjänsten som upprätthålls av biblioteket vid Östra Finlands universitet på adressen: http://epublications.uef.fi/pub/urn_isbn_978952-61-2097-3/. Jur.dr, docent Jussi Pajuoja vid riksdagens justitieombudsmans kansli och pol.dr, docent Mikko Aaltonen vid Helsingfors universitet fungerade som doktorsavhandlingens förhandsgranskare och som opponenter vid disputationen. Jur.dr, professor i straff- och processrätt Matti Tolvanen vid Östra Finlands universitet fungerade som kustos vid disputationen.

2. Statistikcentralen: Finlands officiella statistik (FOS): Åtalade, dömda och straff [nätpublikation]. Helsingfors 2015. <http://www.stat.fi/til/syyttr/tau_sv.html>; Statistikcentralen: Finlands officiella statistik (FOS): Hovrätternas avgöranden [nätpublikation]. Helsingfors 2016. <http://www.stat.fi/til/hovoikr/tau_sv.html>; Statistikcentralen: Finlands officiella statistik (FOS): Tingsrätternas avgöranden i brottmål [nätpublikation]. Helsingfors 2016 $<$ http://www.stat.fi/til/koikrr/tau_sv.html $>$. 
3. Se Gregory Mitchell: Evaluating Judges. In David Klein - Gregory Mitchell (eds.): The Psychology of Judicial Decision Making. American Psychology-Law Society Series. Oxford University Press 2010 p. 221-248 p. 224.

4. Bl.a. Nousiainen, Tapio: Rangaistuksen määräämisestä: erityisesti silmällä pitäen tuomarin mittaamistoimintaa oikean rangaistusmäärän tavoittamiseksi normaalilatitudin puitteissa. Suomalaisen Lakimiesyhdistyksen julkaisuja A-sarja N:o 65. Vammala 1961; LappiSeppälä, Tapio: Rangaistuksen määräämisestä I. Teoria ja yleinen osa. Suomalaisen Lakimiesyhdistyksen julkaisuja A-sarja N:o 173. Vammala 1987.

5. Lappi-Seppälä, Tapio: Tuomioistuinten asema ja tehtävät rangaistuksen määräämisessä. Oikeus 2/1977 s. 117-124, s. 117.

6. Laakso, Seppo: Lainopin teoreettiset lähtökohdat. Tampereen yliopisto, Johtamiskorkeakoulu, Oikeustieteet. Tampere 2012, s. 75.

7. Siltala, Raimo: Johdatus oikeusteoriaan. Forum-iuris. Helsingin yliopiston oikeustieteellisen tiedekunnan julkaisuja. Helsinki 2001, s. 70.

8. Lindroos-Hovinheimo, Susanna: Oikeuden rajoilla. Helsingin yliopiston oikeustieteellisen tiedekunnan julkaisuja. Helsinki 2014, s. 83-84.

9. Se Backman, Eero: Oikeustiede yhteiskuntatieteenä. Tutkimuksia oikeustieteen luonteesta erityisesti rikosoikeuden kannalta. Lakimiesliiton Kustannus. Helsinki 1992, s. 180-218; Siltala, Raimo: Oikeudellinen tulkintateoria. Suomalaisen Lakimiesyhdistyksen julkaisuja A-sarja N:o 261. Helsinki 2004, s. 186-187; Helin, Markku: Lainoppi ja metafysiikka. Tutkimus skandinaavisen oikeusrealismin tieteenkuvasta ja sen vaikutuksesta Suomen siviilioikeuden tutkimuksessa vuosina 1920-1960. Suomalaisen Lakimiesyhdistyksen julkaisuja A-sarja n:o 178. Vammala 1988, s. 7.

10. Aarnio, Aulis: Tulkinnan taito. Ajatuksia oikeudesta, oikeustieteestä ja yhteiskunnasta. WSOY. Helsinki 2006, s. 149-150.

11. Tarukannel, Veijo - Savela, Antti: Suomessa riittäisi kaksi tuomioistuinta. 26.8.2016. $<$ http://www.hs.fi/paakirjoitukset/art-2000002917789.html>.

12. Åtminstone i fråga om våldsbrott, sexualbrott och ekonomiska brott skulle det behövas fästpunkter som styr påföljdsprövningen. Nuutila, Ari-Matti: "Law in Books" ja "Law in Action" - seuraamusharkintaa lainkäytössä. I verket Nuutila, Ari-Matti - Pirjatanniemi, Elina: Rikos, rangaistus ja prosessi. Juhlajulkaisu Eero Backman 1945 - 14/5 - 2005. Turun yliopiston oikeustieteellisen tiedekunnan julkaisuja. A. Juhlajulkaisut N:o 15. Turun yliopisto, oikeustieteellinen tiedekunta 2005 s. 245-259, s. 249.

13. Melander, Sakari: Yhdenvertaisuus rikosoikeudessa. Oikeus 2/2011, s. 175-198, s. 193.

14. Melander, Sakari: Rangaistuskäytäntö ja sen muuttaminen rikosoikeudellisena erityiskysymyksenä. Esitys Suomalaisen Lakimiesyhdistyksen jäsentilaisuudessa 16.3.2015.

15. Högsta domstolens årsberättelse 2015, s. 3.

16. Gustafsson, Mikko - Huuskonen, Janne - Peltola, Mia: Oikeusjutut alkavat pitkittyä jo alkumetreillä. Karjalainen 6.5.2016, s. A12.

17. Keinänen, Anssi: Yhdyskuntapalvelu empiirisen kriminologisen tutkimuksen kohteena. Joensuun yliopisto. Joensuu 2008, s. 15.

18. Keinänen, Anssi - Väätänen, Ulla: Empiirinen oikeustutkimus - mitä ja milloin? Edilex 2015/7. <www.edilex.fi/artikkelit/14917>, s. 3. 
19. Se Anttila, Inkeri - Törnudd, Patrik: Kriminologia ja kriminaalipolitiiikka. Suomalaisen Lakimiesyhdistyksen julkaisuja B-sarja N:o 194. WSOY. Juva 1983, s. 48.

20. Takala, Hannu: Rikostilastot ja rangaistuskäytännön seuranta. I verket Rangaistuksen mittaamisesta. Lakimiesliiton koulutuskeskuksen julkaisusarja n:o 29. Suomen Lakimiesliiton Kustannus Oy. Helsinki 1980 s. 45-68, s. 48.

21. Se Statistikcentralen: Domstolsstatistik läggs ned. Nyheter 27.1.2015. <http:/www.stat.fi/ ajk/tiedotteet/2015/uutinen_002_2015-01-27_sv.html>; SS 1074/2014 rd: Skriftligt spörsmål: upphörande med domstolsstatistik.

22. Se Keinänen 2008, s. 12-13. 